\title{
Scenario of the twins with suspected congenital rubella syndrome (CRS) in Yangon, Myanmar
}

\author{
Kyaw-Zin Thant ${ }^{15^{*}}$, Aye-Aye Thein ${ }^{2}$, San-San Myint ${ }^{2}$, \\ Thein-Thein Myint ${ }^{3}$ and Shigetaka Katow ${ }^{4}$ \\ Accepted 14, September, 2007
}

\begin{abstract}
Rubella is a common cause of childhood rash and fever. Congenital rubella syndrome (CRS) can lead to deafness, heart disease, cataracts, and a variety of other permanent manifestations. In order to identify the disease burden of rubella infection, CRS surveillance among infants in Yangon was conducted for two consecutive years from December 2000 to December 2002, as a WHO-funded study. Among the 13 participating hospitals, the Special Care Baby Unit of the Central Women's Hospital in Yangon reported 17 infants with suspected CRS. Interestingly, three sets of twins with suspected CRS were reported. One $\mathrm{ml}$ of blood was collected from each infant after obtaining informed consent, then tested for the presence of rubella antibody (Immunoglobulin M and G) by the ELISA method, and for the presence of rubella viral RNA by the RT-PCR method. Furthermore, nucleotide sequencing and genotype identification of samples from two cases with positive rubella RNA were performed. All 3 sets of twins were IgM negative. However, rubella RNA was detected by RT-PCR in twin 1A who showed no obvious clinical signs, and in twin 2B who had patent ductus arteriosus, splenomegaly and hepatomegaly. Nucleotide sequences of PCR positive cases revealed genotype Ia sequences. Twin $2 \mathrm{~B}$ was identified as having deafness of the left ear on audiometry assessment conducted at 5 years and 4 months of age. Both twins of twin set- 2 were IgG positive at age 12 days, but turned out to be negative by the age of 9 months. Both twins of twin set- 3 presented with splenomegaly and died before 2 months of age, probably due to other infections. Our findings revealed the different scenario of twins with suspected CRS. It is expected to serve as a valuable addition to the medical literature as there were very few reports on twins with CRS.
\end{abstract}

Keywords: Myanmar; Congenital rubella syndrome (CRS); Twins

\section{INTRODUCTION}

Rubella virus generally causes a mild fever and rash. However, transplacental infection of the foetus with rubella, usually encountered in the first trimester of pregnancy as a consequence of maternal rubella infection, often results in various developmental abnormalities in the newborn infant. These abnormalities, which include cardiac and ocular lesions, deafness, microcephaly, mental retardation, and generalized growth retardation, are designated as congenital rubella syndrome (CRS) [1].

During the period from $1^{\text {st }}$ December 2000 to $31^{\text {st }}$ December 2002, the WHO-funded study on CRS surveillance in children 0-17 months of age was conducted in Yangon,
Myanmar at all 13 hospitals with paediatric services, including specialist hospitals for ophthalmology, otorhinolaryngology, and obstetrics, and also at the two leading private clinics. This surveillance system for CRS was established for the first time in Myanmar in order to identify the disease burden of rubella infection in the capital city of Yangon and to help public health administrators choose appropriate control strategies [2].

Among the 13 participating hospitals, the Special Care Baby Unit of the Central Women's Hospital in Yangon reported 17 infants with suspected CRS including 3 sets of twins. There were very few reports in the medical literature about twins with CRS. To the best of our knowledge, there is no literature on both twins with apparent CRS. Therefore,

${ }^{1}$ Department of Medical Research (Upper Myanmar), Pyin Oo Lwin, Myanmar

${ }^{2}$ Special Care Baby Unit, Central Women's Hospital, Yangon, Myanmar

${ }^{3}$ Department of Child Health, University of Medicine (1), Yangon, Myanmar

${ }^{4}$ Department of Virology III, National Institute of Infectious Diseases, Tokyo, Japan Present address: RIKEN Center of Research Network for Infectious Diseases, Tokyo, Japan

${ }^{5}$ Department of Molecular Epidemiology, Institute of Tropical Medicine, Nagasaki University, Japan

* Corresponding author

Dr. Kyaw-Zin Thant

Department of Molecular Epidemiology, Institute of Tropical Medicine, Nagasaki University, 1-12-4 Sakamoto, Nagasaki 852-8523, Japan

E-mail address: thantkz@nagasaki-u.ac.jp 
the authors presented this as the first report in Myanmar medical literature with special focus on twins with suspected CRS.

\section{MATERIALS AND METHODS}

\section{Subjects and duration of the study}

CRS surveillance study was conducted for a 25 -month period (from $1^{\text {st }}$ December 2000 to $31^{\text {st }}$ December 2002) among children 0-17 months old with clinically suspected CRS who were admitted to one of the 13 study hospitals in Yangon. CRS case definitions were based on the WHO guidelines for surveillance of CRS and rubella [3].

The subjects were children who were: (a) 0-17 months old when seen at the study hospitals, (b) both sexes, (c) fulfilled the suspected CRS case definition laid down by the WHO, and (d) whose parents or guardians gave written informed consent to allow the investigators to collect blood samples. Those who did not fulfill the above criteria were excluded.

\section{Case definitions}

Case definitions were modified from the WHO guidelines mentioned previously [2]. As for suspected CRS, a child aged 0-17 months was defined as having suspected CRS if there was a maternal history of suspected or confirmed rubella during pregnancy and/or a physician detected at least one of the following clinical signs: congenital heart disease, suspicion of deafness, cataract, glaucoma, pigmentary retinopathy, purpura, splenomegaly or microcephaly.

As for laboratory-confirmed CRS, a child aged 0-17 months was defined as having laboratory-confirmed CRS if the child was suspected of having CRS and a serum sample was positive for rubella-specific IgM; and/or positive for rubella-specific $\mathrm{IgG}$ at age 6-17 months (only if the child had not received rubella vaccine and had no history of febrile rash illness); and/or positive for rubella RNA by reverse transcriptase-polymerase chain reaction (RT-PCR).

\section{Ethical considerations}

The study was reviewed and approved by the Ethical Committee on Medical Research Involving Human Subjects, Department of Medical Research (Lower Myanmar), Yangon, and the WHO Secretariat Committee on Research Involving Human Subjects, Geneva, Switzerland.

\section{Sampling procedures}

The objectives and procedures of the study were explained to the parents of each child meeting the suspected CRS case definition, and the child was enrolled in the study with their written informed consent. For each child enrolled, a standard clinical examination was performed, and a 1-ml blood sample was collected. A questionnaire was administered to the mother concerning the child's medical history as well as her history during the pregnancy, including any diagnosis of rubella in the first trimester of pregnancy. A 5$\mathrm{ml}$ blood sample was also collected from the mother to assess the maternal rubella antibody status.

\section{Laboratory procedures}

The blood samples were kept at the study hospitals for a few hours at $4-8^{\circ} \mathrm{C}$ before being transferred to the Virology Research Division, Department of Medical Research (Lower Myanmar), Yangon. Sera were separated and stored at $-70{ }^{\circ} \mathrm{C}$ until further use.

All 81 sera collected from suspected CRS cases were tested for rubella IgM using a commercial ELISA kit (Human GmbH, Germany) according to the manufacturer's instructions. A subset of 57 specimens (70\%) with sufficient serum was tested for rubella $\mathrm{IgG}$ using a commercial ELISA kit (Rubenostika IgG II, Bio Merieux, The Netherlands), according to the manufacturer's instructions.

Another subset of 39 specimens (48\%) with serum remaining was also tested for the presence of rubella virus genome by the reverse transcription-nested polymerase chain reaction (RT-nested PCR) method at the National Institute of Infectious Diseases (NIID), Tokyo, Japan [4]. DNA fragments covering the whole $\mathrm{E} 1$ gene of the rubella virus for genome positive specimens were synthesized using the RT-PCR method. The resulting PCR products were directly sequenced [5], and the phylogenetic tree using whole E1 gene sequence was constructed for genotype identification[6].

\section{RESULTS}

Out of 81 cases with suspected CRS reported during the study period, 17 cases were from the Special Care Baby Unit (SCBU) of the Central Women's Hospital (CWH), Yangon. Interestingly, 3 sets of twins were included among them.

Table 1 shows the clinical and laboratory data of the twins with suspected CRS in Yangon, Myanmar.

Twin set (1) was delivered in December 2000 at CWH by urgent Lower Segment Caeserian Section (LSCS) due to dribbling at 34 weeks gestation. Twin 1A (elder one) is male and twin 1B (younger one) is female. Their birth weights were $1.7 \mathrm{~kg}$ and $1.93 \mathrm{~kg}$, respectively. Because of the prematurity with dribbling, they were sent to the SCBU, CWH. Blood samples were taken on the $12^{\text {th }}$ day postdelivery. On clinical examination, twin 1A showed no obvious signs compatible with suspected CRS case definition while twin 1B revealed suspected congenital heart disease (murmurs probably due to patent ductus arteriosus PDA) and splenomegaly. The mother (33 years old) had a history of febrile rash illness in the first trimester of pregnancy, and 
Table 1. Clinical and laboratory data of twins with suspected CRS in Yangon, Myanmar

\begin{tabular}{|c|c|c|c|c|c|c|c|c|c|c|}
\hline \multirow{2}{*}{\multicolumn{2}{|c|}{ Twin }} & \multirow{2}{*}{ Sex } & \multirow{2}{*}{$\begin{array}{l}\text { Age at } \\
\text { exam: }\end{array}$} & \multirow{2}{*}{$\begin{array}{c}\text { Maternal } \\
\text { history }\end{array}$} & \multirow{2}{*}{ Clinical signs } & \multirow{2}{*}{ Follow-up (at the age) } & \multicolumn{3}{|c|}{ Laboratory findings } & \multirow{2}{*}{ Classification } \\
\hline & & & & & & & $\operatorname{IgM}$ & $\mathrm{IgG}$ & PCR & \\
\hline \multirow[t]{2}{*}{1} & A & M & $\begin{array}{c}12 \\
\text { days }\end{array}$ & + & - & $\begin{array}{l}\text { Healthy ( } 5 \text { years and } \\
6 \text { years } 7 \text { months) }\end{array}$ & - & + & $\begin{array}{c}+ \\
\text { Genotype } \\
\text { 1a } \\
\text { sequenced }\end{array}$ & CRI \\
\hline & B & $\mathrm{F}$ & $\begin{array}{c}12 \\
\text { days }\end{array}$ & + & $\begin{array}{c}+ \\
\text { PDA } \\
\text { Splenomegaly }\end{array}$ & $\begin{array}{l}\text { Healthy ( } 5 \text { years and } \\
6 \text { years } 7 \text { months) }\end{array}$ & - & - & ND & $\begin{array}{l}\text { Clinical- } \\
\text { Confirmed } \\
\text { CRS }\end{array}$ \\
\hline \multirow[b]{2}{*}{2} & A & $\mathrm{F}$ & $\begin{array}{c}12 \\
\text { days }\end{array}$ & - & - & $\begin{array}{l}\text { Healthy ( } 3 \text { years } 8 \text { months } \\
\text { and } 5 \text { years } 4 \text { months) }\end{array}$ & - & $\begin{array}{c}+ \text { at12 } \\
\text { days, - at } \\
9 \text { months }\end{array}$ & - & Non-CRS \\
\hline & B & M & $\begin{array}{c}12 \\
\text { days }\end{array}$ & - & $\begin{array}{c}+ \\
\text { PDA } \\
\text { Splenomegaly } \\
\text { Hepatomegaly }\end{array}$ & $\begin{array}{l}\text { Deafness Left ear } \\
\text { (5 years } 4 \text { months) }\end{array}$ & - & $\begin{array}{c}+ \text { at12 } \\
\text { days, - at } \\
9 \text { months }\end{array}$ & $\begin{array}{c}+ \\
\text { Genotype } \\
\text { la } \\
\text { sequenced }\end{array}$ & $\begin{array}{c}\text { Laboratory- } \\
\text { Confirmed \& } \\
\text { Clinical-Confirmed } \\
\text { CRS }\end{array}$ \\
\hline \multirow{2}{*}{3} & A & $\mathrm{F}$ & $\begin{array}{c}4 \\
\text { days }\end{array}$ & - & $\begin{array}{c}+ \\
\text { Splenomegaly }\end{array}$ & Died (51 days) & - & + & - & Undetermined \\
\hline & B & $\mathrm{F}$ & $\begin{array}{c}4 \\
\text { days }\end{array}$ & - & $\begin{array}{c}+ \\
\text { Splenomegaly }\end{array}$ & Died (54 days) & - & + & - & Undetermined \\
\hline
\end{tabular}

$\mathrm{PDA}=$ Patent ductus arteriosus, $\mathrm{PCR}=$ Polymerase chain reaction, $\mathrm{ND}=$ Not done,

$\mathrm{CRI}=$ Congenital rubella infection, $\mathrm{CRS}=$ Congenital rubella syndrome

another episode of fever in the second trimester. The laboratory test results were negative for rubella $\operatorname{IgM}$ antibody in both twins and mother, but positive for rubella IgG antibody in twin $1 \mathrm{~A}$ and mother. PCR results were positive for twin 1 $\mathrm{A}$, and subsequent nucleotide sequencing showed genotype Ia sequence [7]. PCR could not be performed for twin 1B as there was a lack of remaining serum. Twin 1B was classified as clinically-confirmed CRS because of the presence of one clinical sign from group (a) (i.e. congenital heart disease) and one from group (b) (i.e. splenomegaly) with strong maternal history. However, echocardiogram was not performed at that time for the suspected congenital heart disease (PDA) in twin 1B. In contrast, twin 1A had no obvious clinical signs, but the positive PCR result with sequence data led to the diagnosis of congenital rubella infection (CRI). The positive IgG antibody in twin $1 \mathrm{~A}$ may be maternally-derived IgG. Follow-up visits and medical checkups at 5 years of age found both twins to be apparently healthy, with normal milestones and no detectable features of CRS. Fortunately, they escaped from the permanent structural manifestations of CRS. The most recent followup was done at the age of 6 years and 7 months. Echocardiography and otorhinolaryngological examinations including conventional audiometry assessment were performed. The results were normal for both twins.

Twin set (2) was delivered in March 2002 at CWH by normal spontaneous vaginal delivery. Twin $2 \mathrm{~A}$ is female and twin $2 \mathrm{~B}$ is male. Their birth weights were $1.87 \mathrm{~kg}$ and $1.41 \mathrm{~kg}$, respectively. Blood samples were taken on the $12^{\text {th }}$ day post-delivery. On clinical examination, twin $2 \mathrm{~A}$ showed no obvious signs compatible with suspected CRS while twin 2B revealed suspected congenital heart disease (murmur probably due to PDA) with hepatosplenomegaly. The mother (26 years old) had no history of febrile rash illness during pregnancy. Twin 2B was admitted at the SCBU for two months. The growth chart lay within the acceptable limits by that time. The laboratory test results for IgM were negative in both twins and mother but positive $\mathrm{IgG}$ for rubella in both twins and mother. However, the IgG level in both twins turned out to be negative by the age of 9 months, suggesting that the presence of $\operatorname{IgG}$ in the twins was maternally-derived. PCR results were negative for twin $2 \mathrm{~A}$ and positive for twin $2 \mathrm{~B}$, and subsequent nucleotide sequencing showed genotype Ia sequence. Therefore, twin $2 \mathrm{~A}$ was assumed to be a normal (non-CRS) child, while twin 2 B was classified as laboratory-confirmed and clinically confirmed CRS. However, echocardiogram was not performed for the suspected congenital heart disease (PDA) in twin 2B. Follow-up visit and medical checkup at 3 years and 8 months post-delivery revealed twin $2 \mathrm{~A}$ to be apparently healthy with normal milestones, while twin $2 \mathrm{~B}$ showed delayed milestones, slurring of speech, protrusion of the eyeballs and retarded growth compared to the normal twin $2 \mathrm{~A}$. The twins started kindergarten in June 2005 (at age 3 years and 8 months). The most recent follow-up was done at the age of 5 years and 4 months. Echocardiography and otorhinolaryngological examinations including conventional audiometry assessment were performed. The echocardiogram showed normal results, but twin 2B had deformed external ears with both bone and nerve deafness of the left ear on 
audiometry assessment.

Twin set (3) was delivered in May 2002 at CWH. Twin $3 \mathrm{~A}$ was delivered by forceps delivery and twin $3 \mathrm{~B}$ by normal spontaneous vaginal delivery. Both twins were female and their birth weights were $2.12 \mathrm{~kg}$ and $1.62 \mathrm{~kg}$, respectively. Blood samples were taken on the $4^{\text {th }}$ day postdelivery. On clinical examination, both twins revealed only one minor clinical sign (splenomegaly). The mother (20 years old) had no history of febrile rash illness during pregnancy. Laboratory test results showed negative $\operatorname{IgM}$ in both twins and mother but positive IgG in all three. PCR results were negative for both twins. Twin 3A died in Yangon Children Hospital at age 51 days due to severe pneumonia with epilepsy leading to septicaemia and death. Twin 3B died at home at age 54 days. The mortality in both twins was probably due to other systemic infections.

\section{DISCUSSION}

All three sets of twins in this study were delivered in CWH, Yangon, and were subsequently transferred to the Special Care Baby Unit for intensive care. CWH is an 800bed special hospital with 100 sanctioned neonatal beds for sick babies, and it is the largest hospital for maternity care in the country.

Twin set 1, 2 and 3 are diamniotic monochorionic, diamniotic dichorionic, and monoamniotic monochorionic, respectively. There is no specific twin registry in Myanmar at the country level. However, one study conducted at the CWH in 1993 revealed an overall incidence of $1.3 \%$ for twin pregnancy, with a twin singleton ratio of 1:75 [8]. More recent data from the $\mathrm{CWH}$ hospital registry showed that there were 8973 singleton deliveries with 120 twin deliveries $(1.3 \%)$ and 4 triplet deliveries at $\mathrm{CWH}$ in the year 2002.

When the rubella infection is acquired in the first 12 weeks of pregnancy, it usually results in congenital infections associated with one or more severe defects in 80-90\% of cases. When maternal infection occurs between 13 and 20 weeks, the risk of congenital anomalies declines to approximately $17 \%$. In some cases, there is serological evidence of infection, but no virus is excreted and no anomalies occur [1], a condition referred to as congenital rubella infection (CRI).

There was a case report from Taiwan on monozygotic twins born from a mother with subclinical rubella infection during gestation. Both twins were premature and small for their age. One of the twins suffered congenital rubella infection related to strong positive rubella $\operatorname{IgM}$ antibody for more than 3 months and persistent IgG antibody for more than one year. The baby did not have a defective appearance, but the auditory brainstem evoked potential test (ABEP test) showed abnormal findings. The other twin escaped from congenital rubella infection because of fading rubella IgG antibody within 3 months and negative IgM [9]. In monozygotic twins, vessel communication usually exists and the escape of one twin from rubella is rare. There was only one other case report in the English literature. In that report, both twins had laboratory evidence of rubella infection but only one had clinical manifestations of the disease [10].

With regard to maternal history, only one of three mothers in our twin study had a positive history of fever and rash during pregnancy. A study conducted in Bangladesh revealed that, among mothers of seropositive hearingimpaired children, only $41 \%$ had a positive maternal history [11]. Another study reported that $25 \%$ of the cases were without maternal history [12].

Definitive laboratory test results can be expected among infants with 3 or more predictive signs of CRS. However, testing is also important for those who have 1 or 2 signs consistent with CRS but who lack the classical triad of hearing impairment, heart defects and cataracts [13]. One study showed that $35 \%$ of infants with laboratoryconfirmed CRS had hearing impairment only, $11 \%$ had cardiac defects only, and $1 \%$ had only cataracts [14].

Studies have indicated that hearing impairment is the most common single defect associated with CRS [15], that sensorineural deafness is the most common defect resulting from intrauterine infection with rubella [16], and that it is usually bilateral but can be unilateral [17]. In our study, twin $2 \mathrm{~B}$ revealed bone and nerve deafness of the left ear (unilateral deafness) upon audiometry assessment done at the age of 5 years and 4 months. This finding supports the conjecture that the rubella virus infects only a small number of foetal cells, or discrete foci of cells $[18,19]$.

Structural congenital heart defects are classic findings in infants with CRS. Among infants with CRS and congenital heart defects, most (90\%) exhibit 'flow' defects, especially patent ductus arteriosus $(20 \%)$ and peripheral pulmonic stenosis (10-20\%) [20]. It is also suggested that approximately $30 \%$ of infants with CRS have PDA [21].

The PDA in twins $1 \mathrm{~B}$ and $2 \mathrm{~B}$ were diagnosed only by auscultation of murmurs at the beginning of treatment. The PDA in twin 1B, who was born preterm at 34 weeks gestation, might be due to prematurity. Because PDA is not uncommon even in full term infants, chance alone dictates that the condition might occur occasionally together with other symptoms in an otherwise healthy infant [13].

Twins $1 \mathrm{~B}$ and 2B underwent echocardiography assessment in July 2007 at the age of 6 years and 7 months, and 5 years and 4 months, respectively. No abnormalities were detected, indicating that the PDA in early infancy in these 
cases was only a transient structural manifestations that could be managed medically at the Special Care Baby Unit.

Twins $3 \mathrm{~A}$ and $3 \mathrm{~B}$ had only one minor clinical sign (splenomegaly) without serological evidence of infection other than IgG positivity at 4 days of age, which may have been a maternally derived antibody. The positive predictive value of splenomegaly as a single sign seems to be low for diagnosis of CRS. In "1999 Revisions to the clinical description and laboratory criteria for the CRS case definition for the United States", splenomegaly was replaced by hepatosplenomegaly and mental retardation was deleted in category (B) [20].

Indeed, twin 2B in our study presented with both splenomegaly and hepatomegaly and was confirmed as CRS both clinically and by laboratory means. However, among the 81 cases with suspected CRS encountered during the active surveillance performed in Yangon, Myanmar, we identified one case of IgM proven CRS in a 4 month-old baby presenting with only the single sign of splenomegaly. There was also a strong maternal history with positive IgG antibodies in both mother and baby [ Kyaw-Zin Thant, unpublished data].

Splenomegaly is usually secondary to systemic illness, signifying an abnormality of the lymphoid, reticuloendothelial, or vascular components of the spleen. The most common cause of splenomegaly is infection, but other categories include haematologic, metabolic, vascular, neoplastic, congestive states and miscellaneous disorders. Therefore, it is important to differentiate the splenomegaly of CRS and splenomegaly from other causes by solid proof of maternal rubella infection and rubella-specific laboratory test results.

The third pair of twins in our study is less likely to be associated with CRS than the other two pairs. As they expired before two months of age, we were unable to do the necessary follow-ups.

Bloom et al. conducted the rapid retrospective assessment of CRS burden in Morocco. They cited ophthalmology departments and outpatient cardiology clinics as the most promising sources for CRS case findings [22]. However, our twins did not present significant ophthalmic manifestations, nor was the PDA in twins $1 \mathrm{~B}$ and $2 \mathrm{~B}$ proven by echocardiography.

Peckman described a group of babies who were born normally from mothers with rubella infection during the $1^{\text {st }}$ and $2^{\text {nd }}$ trimester. He found that $23 \%$ of the babies developed congenital rubella-like defects during the 8-year follow-up [23]. It is advisable to trace our cases for the late onset of disorders due to congenital rubella infection. Unlike the variety of abnormalities encountered in infection cases during the first trimester, it has been suggested by some authors that the only defect, when the viraemia of ru- bella occurs in the $13^{\text {th }}$ to $16^{\text {th }}$ week of gestation, is psychomotor retardation of various degrees and possibly deafness [24].

The negative $\operatorname{IgM}$ antibody in all our twins may be due to the low sensitivity of the commercial kit arising from the antigenic difference between the virus strains used in the kit and those prevailing in Myanmar. Another possibility, as pointed out in the comment of Dr. L.Z. Cooper, is that rubella IgM antibody titres may not be detectable before age1 month in approximately $20 \%$ of infants tested when the comparisons have been made between results of serologic tests and virus cultures. It was recommended to re-test the IgM negative infants at 1-month old [13, 25, 26].

For virus genome detection by RT-PCR, there could be reduced sensitivity because of inappropriate storage of sera after sampling, such as refrigeration above $-80^{\circ} \mathrm{C}$, repeated freeze-thawing to detect rubella specific antibody, and transportation before RNA extraction.

Our present findings revealed the different scenario of twins with suspected CRS and constitute the first report on twins with rubella infection in the Myanmar medical literature.

\section{ACKNOWLEDGEMENTS}

The authors would like to express their gratitude to WHO-Vaccines and Biologicals, Geneva, Switzerland, for its financial support for the surveillance study conducted at the DMR (Lower Myanmar). Thanks go to Dr. Susan E. Robertson from the WHO for her supervision and encouragement throughout the study. Thanks also go to the Takeda Science Foundation, Osaka, Japan, for allowing the principal investigator to conduct RT-PCR testing and nucleotide sequencing at the National Institute of Infectious Diseases, Tokyo, Japan, as a Visiting Research Fellow. Special thanks go to Prof. Dr. Thein Tun and Dr. Ye Myint Kyaw for the audiometry assessment and echocardiography assessment, respectively.

\section{REFERENCES}

1 . Best JM, Banatvala JE (1995) Rubella. In: Zuckerman AJ, Banatvala JE, Pattison JR, editors. Principles and Practice of Clinical Virology. 3rd ed. John Wiley \& Sons Ltd., Chichester, England. p363-400.

2 . Kyaw-Zin-Thant, Win-Mar-Oo, Thein-Thein-Myint, ThanNu-Shwe, Aye-Maung-Han, Khin-Mar-Aye, Kay-Thi-Aye, Kyaw-Moe, Soe-Thein, Robertson SE (2006) Active surveillance for congenital rubella syndrome in Yangon, Myanmar. Bull. World. Health. Organ. 84: 12-20.

3 . Cutts FT, Best JM, Siqueira MM, Engstrom K, Robertson SE (1999) Guidelines for surveillance of congenital rubella 
syndrome and rubella, field test version, May 1999 (WHO document WHO/V\&B/99.22) Geneva, World Health Organization.

4 . Tanemura M, Suzumori K, Yagami Y, Katow S (1996) Diagnosis of fetal rubella infection with reverse transcription and nested polymerase chain reaction: a study of 34 cases diagnosed in fetuses. Am J Obstet Gynecol 174: 578-582.

5 . Katow S, Minahara H, Ota M, Fukushima M (1997) Identification of strain-specific nucleotide sequences in E1 and NS4 genes of rubella virus vaccine strains in Japan. Vaccine 15: 1579-1585.

6 . Kyaw-Zin-Thant, Katow S, Nakajima S, Kato H, Umino Y, Thein-Thein-Myint, Kyaw-Moe, Soe-Thein (2003) Molecular epidemiology of Myanmar rubella virus strains at the beginning of the $21^{\text {st }}$ century. J Clin Virol 28(S): S72.

7 . World Health Organization (2005) Standardization of the nomenclature for genetic characteristics of the wild-type rubella viruses. Weekly Epidemio Rec 80: 126-132.

8 . Myint Myint Shwe (1993) A study of twin pregnancy in Central Women Hospital. Thesis submitted for the Master of Medical Science (Obstetrics and Gynaecology) degree, Institute of Medicine (1), Yangon, Myanmar.

9 . Wang Li-Na, Wang Yng-Fu, Horne Chewn-Chin, Shiao Liu -Ching (1990) Congenital rubella infection: Escape of one monozygotic twin with two amnions, one chorion and single placenta. J Formosan Med Assoc 89 (1): 30-33.

10. Montgomery RC, Stockdell K (1970) Congenital rubella in twins. J Pediatrics 76: 772-773.

11. Rahman MM, Khan AM, Hafiz MM, Ronny FMH, Ara S, Chowdhury SK, Nazir SS, Khan WI (2002) Congenital hearing impairment associated with rubella: lessons from Bangladesh. Southeast Asian J Trop Med Public Health 33: 811-817.

12. Gumpel SM, Hayes K, Dudgeon JA (1971) Congenital perceptive deafness: role of intrauterine rubella. Br Med J 2: 300-304.

13. Zimmerman L, Reef SE (2001) Incidence of congenital rubella syndrome at a hospital serving a predominantly Hispanic population, El Paso, Texas. Pediatrics 107 (3): e40.

14. Reef S, Holliday C, LeBaron C (2000) USA experience with CRS case definition. Presented at the Meeting on Pre- venting Congenital Rubella Syndrome: immunization Strategies, Surveillance Needs; January 12-14, 2000; Geneva, Switzerland.

15 . Cooper L, Ziring P, Ockerse A, Fedun B, Kiely B, Krugman S (1969) Rubella clinical manifestations and management. Am J Dis Child 118: 18-29.

16. Gumpel S (1972) Clinical and social status of patients with congenital rubella. Arch Dis Child 47: 330-337.

17 . Sheridan MD (1964) Final report of a prospective study of children whose mothers had rubella in early pregnancy. $\mathrm{Br}$ Med J 11: 536-539.

18. Lee J-Y, Bowden DS (2000) Rubella Virus Replication and Links to Teratogenicity. Clin Microbiol Reviews 13 (4): 571-587.

19. Diamanti A, Pietrobattista A, Bevivino E, Angelis PD, Calce A, Oglio LD, Gambarara M (2006) Duodenal stenosis, a new finding on congenital rubella syndrome: case description and literature review. J Inf 53: e207-e210.

20 . Reef SE, Plotkin S, Cordero JF et al. (2000) Preparing for Elimination of Congenital Rubella Syndrome (CRS): Summary of a Workshop on CRS Elimination in the United States. Clin Infect Dis 31: 85-95.

21 . Cherry J (1992) Rubella. In: Feigin R, Cherry J, eds. Textbook of Pediatric Infectious Diseases. $3^{\text {rd }}$ ed. Philadelphia, PA; WB Saunders; 1792-1817.

22 . Bloom S, Rguig A, Berraho A et al. (2005) Congenital rubella syndrome burden in Morocco: a rapid retrospective assessment. Lancet 365: 135-141.

23. Peckman CS (1972) Clinical and laboratory study of children exposed in utero to maternal rubella. Arch Dis Child 47: 571-577.

24. Michaels RH, Mellin GW (1960) Perspective experience with maternal rubella and associated congenital malformations. Pediatrics 26: 200.

25. Centers for Disease Control and Prevention (1997) Manual for the Surveillance of Vaccine Preventable Diseases. Atlanta, GA.

26. Katow S (2004) Surveillance of congenital rubella syndrome in Japan, 1978-2002: effect of revision of the immunization law. Vaccine 22: 4084-4091. 